\section{Bosentan and sildenafil in the treatment of HIV-associated pulmonary hypertension}

\section{Pierangelo Chinello, ${ }^{1}$ Stefania Cicalini, Andrea Cortese, ${ }^{2}$ Maria Paola Cicini, ${ }^{3}$ Nicola Petrosillo ${ }^{1}$}

'Second Infectious Diseases Unit, L. Spallanzani National Institute for Infectious Diseases, Rome; 2U.O. Diagnostica per Immagini, S. Camillo-Forlanini Hospital, Rome; 3III Cardiology Unit, S. Camillo-Forlanini Hospital, Rome, Italy

\section{Abstract}

We present the case of an HIV/HCV-coinfected patient with HIV-related pulmonary hypertension (HRPH) who experienced a good clinical and functional response to bosentan, with a subsequent switch to oral sildenafil due to increased transaminase levels. Bosentan resulted less handy in this case, probably due to both side effects and co-morbidities.

\section{Introduction}

In the current guidelines for treatment of pulmonary arterial hypertension (PAH), therapeutic options for HIV-related pulmonary hypertension (HRPH) are less well established as compared to other forms of $\mathrm{PAH},{ }^{1}$ and there are still controversial data on the role of the antiretroviral therapy (ART) in the management of patients with HRPH. ${ }^{2}$ The classes of drugs currently approved as specific therapy for PAH include the prostacyclin analogues, the endothelin receptor antagonists, and the oral phosphodiesterase type 5 (PDE5) inhibitors. In patients with HRPH the same treatment algorithm as in patients with idiopathic PAH should be considered, taking into consideration co-morbidities and drug-drug interactions. ${ }^{1}$ There is increasing evidence of the efficacy of bosentan in the treatment of HRPH patients. ${ }^{3}$ On the other hand, case reports on HRPH patients treated with sildenafil are scanty. ${ }^{4-9}$ We are presenting a learning experience on the use of bosentan as a first line therapy in a HRPH patient, in comparison with sildenafil.

\section{Case Report}

A 46-year-old HIV positive female patient was admitted on May 2005 in our Infectious Diseases Unit because of asthenia, dyspnoea and peripheral oedema. She was a former drug addict and was on treatment with methadone; she was aware to be HIV and HCV positive (genotype 1) since 1998; she also reported occasional alcohol abuse. On admission her CD4+ cell count was $689 / \mathrm{mmc}$ and HIV viral load was 1972 copies/mL; the liver function tests showed aspartate aminotransferase (AST) $209 \mathrm{U} / \mathrm{L}$, alanine aminotransferase (ALT) $66 \mathrm{U} / \mathrm{L}$, international normalized ratio (INR)1.22, total bilirubin $1.1 \mathrm{mg} / \mathrm{dL}$, cholinesterase $3972 \mathrm{U} / \mathrm{L}$; antinuclear, antimitochondrial, and anti-smooth muscle autoantibodies resulted negative. The patient was naive for ART.

Chest X-ray showed enlarged central pulmonary arteries and clear lung fields. The electrocardiogram revealed right axis deviation, incomplete right bundle branch block, signs of right ventricular overload, prolonged QTc. The transthoracic echocardiography showed systolic flattening of the interventricular septum, enlarged right atrium and ventricle, and a $3^{+}$ tricuspid valve regurgitant jet; the estimated systolic pulmonary artery pressure (PAP) was $60 \mathrm{mmHg}$. Cardiac catheterization confirmed the presence of a severe PAH: the mean PAP (mPAP) was $50 \mathrm{mmHg}$, the pulmonary capillary wedge pressure was $10 \mathrm{mmHg}$, and there was no response to the administration of nitric oxide. The patient was in New York Heart Association (NYHA) functional status class III. The 6-minute walking distance (6MWD) was $460 \mathrm{~m}$. In June 2005 bosentan was started at a $62.5 \mathrm{mg}$ b.i.d dose for 4 weeks and subsequently increased to $125 \mathrm{mg}$ b.i.d. The patient was also given furosemide $25 \mathrm{mg}$ qd and warfarin dosed to maintain the INR between 2 and 3 . In July 2005 the estimated systolic PAP (sPAP) was $50 \mathrm{mmHg}$. In the following months the estimated SPAP was rarely evaluable because of the remarkable reduction of the tricuspid valve regurgitation. Indeed, the patient improved her exercise capacity and reached NYHA functional status class I. In November 2005 her 6MWD was $504 \mathrm{~m}$.

On December $21^{\text {st }}, 2006$ because of an increase in transaminase levels (AST 203, ALT 91) bosentan was stopped. On January $22^{\text {nd }}$, 2007 the patient underwent a new cardiac catheterization that showed an mPAP of 41 $\mathrm{mmHg}$. Due to the persistent increase in transaminase levels, on February $5^{\text {th }}, 2007$ sildenafil $20 \mathrm{mg}$ t.i.d was started as new specific therapy for $\mathrm{PH}$; furosemide $25 \mathrm{mg}$ qd and warfarin were continued. On the same date, the patient underwent a cardiac nuclear magnetic resonance (NMR) that revealed a
Correspondence: Pierangelo Chinello, Second Infectious Diseases Unit, L. Spallanzani”National Institute for Infectious Diseases, Via Portuense 292, 00149 Rome, Italy.

Tel. +39.06.551.702.94 - Fax: +39.06.55170315.

E-mail: pierangelo.chinello@inmi.it

Key words: bosentan, sildenafil, HIV, pulmonary arterial hypertension.

Conflict of interest: the authors report no conflicts of interest.

Received for publication: 11 August 2011.

Revision received: 19 October 2011.

Accepted for publication: 30 October 2011.

This work is licensed under a Creative Commons Attribution NonCommercial 3.0 License (CC BYNC 3.0).

(C) Copyright P. Chinello et al., 2011

Licensee PAGEPress, Italy

Infectious Disease Reports 2011; 3:e14

doi:10.4081/idr.2011.e14

reduced (30\%) ejection fraction of the right ventricle (Figure 1A).

In March 2007 the patient felt better, her 6MWD was $471 \mathrm{~m}$ and her echocardiogram showed a good right ventricle function [tricuspid annular plane systolic excursion (TAPSE) $29 \mathrm{~mm}$ ]. Due to a progressive reduction in CD4+ lymphocytes count, on May $3^{\text {rd }}, 2007$ the patient started ART consisting of Combivir 1 tablet b.i.d. and Reyataz 400 mg q.d. Ritonavir was avoided due to concern about possible interactions with sildenafil. At that time the CD4 ${ }^{+}$lymphocytes were $260 / \mathrm{mmc}$ and the HIV viral load was $10186 \mathrm{cp} / \mathrm{mL}$. The viroimmunological response was good: in August 2007 the CD4+ lymphocytes were $370 / \mathrm{mmc}$ and the HIV viral load was $<50 \mathrm{cp} / \mathrm{mL}$. In October 2007 the cardiologic functional tests were satisfying: the $6 \mathrm{MWD}$ was $569 \mathrm{~m}$, the TAPSE was $25 \mathrm{~mm}$ and the estimated sPAP was $55 \mathrm{mmHg}$. In January 2008 the patient underwent a third cardiac catheterization that showed a further reduction of mPAP to $37 \mathrm{mmHg}$ (Table 1). In February 2008 a second cardiac NMR showed an improved performance of the right ventricle (ejection fraction $46 \%$, Figure 1B).

During the following months the patient continued sildenafil $20 \mathrm{mg}$ t.i.d., reported to have mild exertional dyspnoea and was in NYHA functional status class II. On December $9^{\text {th }}, 2008$ she was last evaluated by the Cardiologist who found her in good general condition: 6MWD 595 m, NYHA functional status class I, no dyspnoea. The CD4+ lymphocytes were $335 / \mathrm{mmc}$ and the HIV viral load was $<50$ $\mathrm{cp} / \mathrm{mL}$. Unfortunately, at the end of December 2008 the patient died in the intensive care unit of a peripheral hospital because of bilateral pneumonia. 


\section{Discussion}

Our case report presents some points of interest.

First, this HRPH patient was successfully treated with bosentan; indeed, during bosentan treatment, she experienced an improvement of exercise capacity: her 6MWD raised from 460 to $504 \mathrm{~m}$ and her NYHA functional class improved from III to I. However, an increase in transaminase levels to $>5$ times the upper limit of normal led to the discontinuation of bosentan. HCV co-infection and/or alcohol abuse could have contributed to the liver damage in this patient. Bosentan is an oral non selective endothelin receptor blocking agent (blocks both endothelin A and B receptors) of proven efficacy in the treatment of PAH. The efficacy of oral bosentan has also been demonstrated in patients with HRPH.,10 In an echocardiographic study of PAH patients treated with bosentan, the right ventricular systolic function improved along with decreased pulmonary vasculature resistance and PAP. ${ }^{11}$ During bosentan therapy, monitoring of liver and haematologic functions is necessary. An increase in liver enzymes to $>3$ times and to $>8$ times the upper limit of normal was observed in $13 \%$ of patients treated with bosentan in the EARLY study ${ }^{12}$ and in $3 \%$ of patients treated with bosentan $125 \mathrm{mg}$ b.i.d in the BREATHE-1 study, ${ }^{13}$ respectively. In the experience of Degano and coll. ${ }^{14}$ bosentan was safe when combined with ART, with no negative impact on HIV infection control. This drug is moreover contraindicated in pregnancy because of its teratogenic potential. Newer selective endothelin A receptor antagonists, i.e. sitaxsentan and ambrisentan, have been investigated for the treatment of $\mathrm{PAH}$ and demonstrated improvements in exercise tolerance and haemodynamics. ${ }^{15-16}$ Only one case of sitaxsentan therapy in a HRPH patient has been reported to date. ${ }^{17}$ The drug has subsequently been withdrawn from the market due to cases of severe liver toxicity.

Second, after bosentan interruption our patient was switched to oral sildenafil with good functional and haemodynamic results. In a double-blinded placebo-controlled study, PDE-5 inhibitor sildenafil was demonstrated to improve exercise capacity, functional class and haemodynamics in patients with PAH. ${ }^{18}$ Sildenafil enhances nitric oxide-dependent cGMP-mediated pulmonary vasodilation through the inhibition of the breakdown of cGMP. Very few cases of HRPH patients treated with sildenafil are reported in the literature..$^{4-9}$ In these cases sildenafil was found to improve dyspnoea and exercise tolerance. No cases of tadalafil (another PDE-5 inhibitor) treatment for HRPH have been reported to date. Caution should be used in HIV-infected patients taking protease inhibitor-based ART regimens since saquinavir, indinavir and particularly ritonavir significantly modify the pharmacokinetics of sildenafil, thereby resulting in increased plasma concentration of both drug and metabolite. ${ }^{19}$ In our patient we chose an unboosted protease inhibitor in order to avoid interactions between sildenafil and ritonavir; furthermore, efavirenz was not a suitable choice for this patient due to her alcohol abuse.

Third, our patient did not start ART at diagnosis of HRPH due to her good viroimmunologic levels, and due to concerns about a possible poor adherence to therapy. The delay in ART initiation does not seem to have worsened the prognosis of this patient: indeed, she experienced a good viroimmunologic response to ART. Although ART seems to be recommendable in all HRPH patients irrespective of their CD4 cells count, based on the observation by Opravil and coll. that five out of eight patients who had significantly stable and decreasing estimated sPAP were receiving antiretroviral therapy, ${ }^{20}$ the role of ART in influencing the outcome of HRPH is controversial. A more favourable outcome seems to be observed in patients treated with ART and PAH specific therapy (PAH-ST) rather than in patients taking ART but without PAH-ST, suggesting that prognosis in HRPH patients is mostly influenced by PAH-ST. ${ }^{2}$

In conclusion, our patient experienced clinical and haemodynamic improvement of her HRPH with both bosentan and sildenafil thera-

Table 1. Cardiac catheterization findings.

\begin{tabular}{|c|c|c|c|c|}
\hline Date & $\operatorname{mPAP}(*)$ & PCWP (*) & $\operatorname{TPR}\left(^{\circ}\right)$ & CI (\#) \\
\hline May 31, 2005 & 50 & 10 & 23.5 & 1.51 \\
\hline Jan 22, 2007 & 41 & 11 & 15.3 & 1.75 \\
\hline $\operatorname{Jan} 29,2008$ & 37 & 11 & 5.6 & 2.5 \\
\hline
\end{tabular}
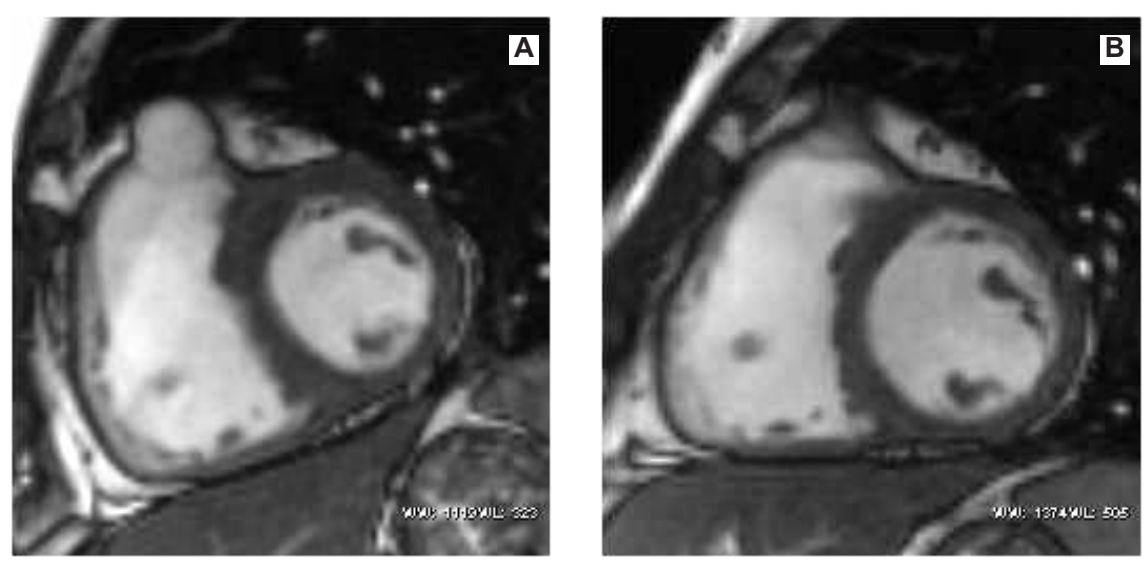

Figure 1. Cardiac nuclear magnetic resonance performed A) before and B) after a 12-month sildenafil therapy. Note the flattening of the interventricular septum with a D-shaped left ventricle in A) and the normal figure of the interventricular septum in B). py. Bosentan resulted less handy in this case, probably due to both side effects and co-morbidities. Sildenafil could be a more suitable first-line therapy for HRPH patients with HCV co-infection and/or alcohol abuse.

\section{References}

1. Galiè N, Hoeper MM, Humbert M, et al. Guidelines for the diagnosis and treatment of pulmonary hypertension: the Task Force for the diagnosis and treatment of pulmonary hypertension of the European Society of Cardiology (ESC) and the European Respiratory Society (ERS), endorsed by the International Society of Heart and Lung Transplantation (ISHLT). Eur Heart J 2009;30:2493-537.

2. Cicalini S, Chinello P, Grilli E, Petrosillo N. Treatment and outcome of pulmonary arterial hypertension in HIV-infected patients: a review of the literature. Curr HIV Res 2009;7:589-96.

3. Sitbon 0, Gressin V, Speich R, et al. Bosentan for the treatment of human immunodeficiency virus associated pulmonary arterial hypertension. Am J Respir Crit Care Med 2004;170:1212-7.

4. Schumacher YO, Zdebik A, Huonker M et al. Sildenafil in HIV-related pulmonary hypertension AIDS 2001;15:1747-8.

5. Carlsen J, Kjeldsen K, Gerstoft J. Sildenafil 
as a successful treatment of otherwise fatal HIV-related pulmonary hypertension. AIDS 2002;16:1568-9.

6. Alp S, Schlottmann R, Bauer TT et al. Longtime survival with HIV-related pulmonary arterial hypertension: a case report. AIDS 2003;17:1714-5.

7. Wong AR, Rasool AH, Abidin NZ et al. Sildenafil as treatment for Human Immunodeficiency Virus-related pulmonary hypertension in a child. J Paediatr Child Health 2006;42:147-8.

8. Aschmann YZ, Kummer 0, Linka A, et al. Pharmacokinetics and pharmacodynamics of sildenafil in a patient treated with human immunodeficiency virus protease inhibitors. Ther Drug Monit 2008;30:130 4.

9. Barnett CF, Hsue PY, Machado RF. Pulmonary hypertension. An increasingly recognized complication of hereditary haemolytic anemias and HIV infection. JAMA 2008;299:324-31.

10. Degano B, Guillaume M, Savale L, et al. HIV-associated pulmonary arterial hyper- tension: survival and prognostic factors in the modern therapeutic era. AIDS 2010;24:67-75.

11. Galiè $\mathrm{N}$, Hinderliter AL, Torbicki $\mathrm{A}$, et al. Effects of the oral endothelin receptor antagonist bosentan on echocardiographic and Doppler measures in patients with pulmonary arterial hypertension. J Am Coll Cardiol 2003;41:1380-6.

12. Galiè $N$, Rubin LJ, Hoeper $M$, et al. Treatment of patients with mildly symptomatic pulmonary arterial hypertension with bosentan (EARLY study): a doubleblind, randomized controlled trial. Lancet 2008;371:2093-100.

13. Rubin LJ, Badesch DB, Barst RJ, et al. Bosentan therapy for pulmonary arterial hypertension. N Engl J Med 2002;346:896903.

14. Degano B, Yaici A, Le Pavec J, et al. Longterm effects of bosentan in patients with HIV-associated pulmonary arterial hypertension. Eur Respir J 2009;33:92-8.

15. Barst RJ, Rich SA, Horn EM et al. Clinical efficacy of sitaxsentan, an endothelin-A receptor antagonist, in patients with pulmonary arterial hypertension. Chest 2002 ; 121:1860-8.

16. Galiè N, Badesh DB, Oudiz R, et al. Ambrisentan therapy for pulmonary arterial hypertension. J Am Coll Cardiol 2005; 46:529-35.

17. Zacà V, Metra $M$, Danesi $R$, et al. Successful switch to sitaxsentan in a patient with HIV-related pulmonary arterial hypertension and late intolerance to non selective endothelin receptor blockade. Ther Adv Respir Dis 2009;3:11-4.

18. Galiè N, Ghofrani HA, Torbicki A, et al. Sildenafil citrate therapy for pulmonary arterial hypertension. N Engl J Med 2005;353:2148-57.

19. Muirhead GJ, Wulff MB, Fielding A, et al. Pharmacokinetic interactions between sildenafil and saquinavir/ritonavir. $\mathrm{Br} \mathrm{J}$ Clin Pharmacol 2000;50:99-107.

20. Opravil M, Pechere M, Speich R, et al. HIVassociated primary pulmonary hypertension. Am J Respir Crit Care Med 1997; 155:990-5. 